\title{
COMPARATIVE STUDY OF CEMENTUM AND DENTIN SHEAR BOND STRENGTH USING RESIN COMPOSITE WITH UNIVERSAL ADHESIVE SYSTEM AND RESIN MODIFIED GLASS IONOMER
}

\author{
Hebatallah M. Taher* and Nermeen Kamal Hamza **
}

\begin{abstract}
Objective: to compare the shear bond strength of resin composite using universal adhesive system containing MDP and resin modified glass ionomer cement to cementum and compare the results with those of cervical dentin. Materials and methods: A total of 12 lower premolars were used in this study, they were sectioned just above the cemento-enamel junction, the roots were then sectioned into two halves and divided into two main groups according to the tooth substrate in which group 1) Cervical dentin and group 2) Cementum. They were further subdivided into two subgroups according to the material used where $n=6$ subgroup 1) Resin composite (Brilliant Ever-Glow) using universal adhesive (One coat 7 universal), subgroup 2) Resin modified glass ionomer (Fuji II LC). Shear bond strength was then evaluated for all specimens and statistically analyzed. Results: There was statistically significant difference between resin composite using universal adhesive system and resin modified glass ionomer when applied on cementum. While on comparing the resin composite using universal adhesive system and resin modified glass ionomer on cervical dentin it showed no statistically significant difference. Meanwhile no statistically significant difference was found between cervical dentin and cementum when using resin composite with universal adhesive system. Comparing resin modified glass ionomer on dentin and cementum there was also no statistical difference. Conclusion: using universal adhesive containing MDP with resin composite it showed the same bond strength to cervical dentin and cementum. While the resin modified glass ionomer showed higher bond strength to cementum than that of the universal adhesive system.
\end{abstract}

\section{INTRODUCTION}

The cervical margin of class II and class V usually located below cemento-enamel margin. This area posses a clinical problem in adhesive resin restorations, since the margins of the cavities are limited by cementum. A calcified tissue exhibiting several histo-morphological and functional variations from dental structure that have been extensively evaluated as bonding substrate (Enamel and Dentin) ${ }^{(1)}$. Cementum is specialized connective tissue covering the outermostlayer of calcified matrix on root surface, with a primary role to connect the

\footnotetext{
* Associate Professor of conservative Dentistry, Cairo University and October University for Modern Science and Art .

** Lecture of conservative Dentistry, October University for Modern Science and Art .
} 
periodontal ligament to the root surface. Cementum has not been largely encountered as a substrate from the bonding point of view, despite the fact that cervical microleakage has been early recognized to contribute to high incidence of secondary caries and fail of restoration. Furthermore, root caries occurs on exposed tooth surface below cemento-enamel junction after gingival recession, with different forms of root surface caries, ranging from minor demineralized discolored areas to extensive yellow brown soft areas with cavitation below the affected cementum.

Most studies on adhesive bonding to root surface deal with bonding mechanism of adhesive systems to exposed cervical dentin surfaces (sound, sclerotic and carious) without giving particular attention to cementum. Meanwhile, cementum occupies the critical cervical marginal edge of the complex cervical restoration extending beyond the cementoenamel junction. Ferrari et $\mathrm{al}^{(2)}$ reported that the cementum treated with dentin bonding system is infiltrated by the resin but the predictability of the bond is unclear ${ }^{(3)}$, meanwhile, Van Diijen ${ }^{(17)}$ reported that in vitro studies revealed moderate to severe leakage in cementum, when the cervical margins are located below cemento-enamel junction. Recent studies evaluated the bond strength of restorative material to the three calcified dental tissues (enamel ,dentin and cementum ) put an important question about the contribution of cervically bonded materials to the mechanical properties of restorations ${ }^{(4,5)}$. Such controversial findings show that our knowledge on bonding to cementum is limited. Furthermore, it is still unclear whether or not the problem of bonding to cementum is related to the structure and properties of the tissue or to a limited effectiveness of the adhesive materials at this area ${ }^{(6)}$.

Adhesion process depends not only on the adhesive system, but also on dental substrate. Clinically, the margins of many adhesive restorations on the root surface are thought to be positioned in cementum or cervical outer dentin ${ }^{(7)}$. The root cementum has high organic content and predominantly consists of cross-linked collagen structure, in which this tissue is less hard and more permeable to variety of materials compared to enamel and dentin ${ }^{(8)}$. Dental cementum has been defined as composite of non-collagenous proteins and collage fibrils reinforced with $65 \%$ by weight inorganic phase (apatite crystals). There are three types of cementum which are acellular afibrillar cementum which covers minor areas of enamel; acellular extrinsic fiber cementum which is mainly found on the cervical and middle portion, and cellular mixed stratified fiber cementum that cover the furcation and the apical root portions ${ }^{(9,10)}$.

Universal adhesives was one of the most recent novelties in adhesive dentistry that have been used since 2011 in clinical practice showing broader application than the seventh generation system of adhesive bonds (self-etching single bottle, or all in one systems) ${ }^{(11)}$, they are known as multi-purpose or multi-mode adhesives due to its ability to be used as etch and rinse adhesives or self-etch. 10 MDP (Methacryloxydecyl di-hydrogen phosphate) monomer was firstly introduced by Panavia adhesive resin cement which showed many positive credits to be used as an effective monomer in universal adhesive composition as being versatile amphiphilic functional monomer with a hydrophilic polar phosphate group on one end (capable of chemical bonding to tooth tissues) while the other end carries hydrophobic methacrylate group (capable of chemical bonding to methacrylate based cements and restoratives). In addition to the long carbon chain back bone which increases the hydrophobicity of the monomer which is considered to be of a great importance for the durability of bond in terms of hindering hydrolysis break down and water sorption at the adhesive interface over time ${ }^{(12)}$.Additionally, the 10 MDP shows an important property that is present in few monomers used in adhesive dentistry which is the ability to bond chemically with tooth 
structure through ionic bonding to calcium ions present in hydroxyapatite crystals ${ }^{(13)}$.

Dealing with acellular afibrillar cementum located mainly around cemento-enamel junction covering minor enamel areas, represents a nonhomogenous matrix composed of multiple calcified layers without collagen fibers and also the acellular extrinsic fiber cementum which is located at the cervical area. Their histo-morphological structure increased the difficulty in bonding using adhesive system and restored with resin composite. Therefore, the aim of our study was to compare the bond strength of 10 MDP universal adhesives and resin modified glass ionomer to human cementum and compare the results with those of cervical dentin.

\section{MATERIALS AND METHODS}

\section{Material}

One Universal adhesive, One Nano-Hybrid Resin Composite and One Resin Modified Glass ionomer were used in this study

The materials used in this study, their composition, and manufacturers are listed in table 1 .

\section{Methods}

\section{Teeth selection}

Twelve extracted lower premolars were selected for this invitro study free from caries or cracks or any damage from extraction. They were extracted for orthodontic reasons. Teeth were cleaned from any de.bris by scaling and stored in distilled water

\section{Grouping of teeth}

Specimens were divided into two groups (12 each) according to the substrate used. Where group 1 represents cervical dentin specimens and group 2 represents cementum specimens. Each main group was subdivided into two subgroups according to the restorative material used, where subgroup 1 represented resin composite using universal adhesive and subgroup2 represented resin modified glass ionomer in which $\mathrm{n}=6$.

\section{Specimen preparation}

Crown were sectioned above cementoenamel junction with double faced diamond disc at low speed. The twelve roots were then split longitudinally in a bucco-lingual

TABLE (1) Materials used in this study

\begin{tabular}{|c|c|c|}
\hline Product & Ingredients & Manufacturer \\
\hline Fuji II LC, & $\begin{array}{l}\text { Powder: } 100 \% \text { fluoro-alumino-silicate glass, } \\
\text { Liquid: } 35 \% \text { HEMA, 25\% distilled water, 24\% polyacrylic acid, } 6 \% \\
\text { tartaric acid and 10\% Camphorquinone, Bis-GAMA, and traces of } \\
\text { TEGDMA }\end{array}$ & $\begin{array}{l}\text { 3M-ESPE Dental } \\
\text { products } \\
\text { St.Paul. MN, USA }\end{array}$ \\
\hline One coat 7 universal & $\begin{array}{l}\text { HEMA, Hydroxypropylmethacrylate, Methacrylate modified } \\
\text { polyacid, Urethane dimethacrylate, glycerol dimethacrylate, } \\
\text { Amorphsilcic acid, water } 5 \% \text {, initiators, stabilizer, MDP }\end{array}$ & $\begin{array}{c}\text { COLTENE Dental } \\
\text { Products }\end{array}$ \\
\hline $\begin{array}{l}\text { Brilliant Ever-Glow } \\
\text { Submicron Hybrid } \\
\text { Composite }\end{array}$ & $\begin{array}{l}\text { Methacrylate, Dental glass, Amorphous silica, Zinc oxide } \\
\text { The inorganic Filler contents: Prepolymerized filler containing } \\
\text { dental glass and nano-silica (sub-micron), Nano-silica aggregated } \\
\text { and non- aggregated } \\
\text { - The filler loading is } 74 \% \text { by weight ( } 56 \% \text { by volume). }(0.02-1.5 \mathrm{~m}\end{array}$ & $\begin{array}{c}\text { COLTENE Dental } \\
\text { Products }\end{array}$ \\
\hline
\end{tabular}


direction giving a total of 24 halves. Each half was embedded in rectangular transparent auto-polymerized acrylic resin block (Acrostone, Egypt) while it was in soft dough stage. The dimensions of the block were $(3.0 \mathrm{~cm} \times 2.0 \mathrm{~cm})$. Half of the specimens were embedded with the dentin surface facing upward while the other halves were imbedded with the cementum surface facing upward

\section{Application of materials}

\section{a) Nano-hybrid resin composite using universal adhesive}

Bonding area was delineated on the specimens with a demographic pencil with area of $4 \mathrm{~mm}$ in diameter. The universal adhesive system was applied on the specimens in self etch mode, in which the adhesive was immediately applied onto the dentin and cementum surface specimens using a disposable applicator. One coat of the adhesive was applied using disposable micro-brushes (Microbrush-International, Grafton, USA). It was applied with agitation for 20 seconds and left undisturbed for 5 seconds, and then air thinned till no movement of the adhesive is observed. The adhesive was left uncured to facilitate fixation of the cut plastic tubes (diameter $3 \mathrm{~mm}$ and height $3 \mathrm{~mm}$ ) on it before packing of the resin composite into them. The disposable Micro-brushes were replaced after each use. Resin composite was then delivered directly from the dispensing tip which was carefully condensed using small condenser to avoid air bubbles. Material was then light cured with the light guide tip held as close as possible to the plastic tube during exposure for 40 seconds..

\section{b) Resin modified glass ionomer}

Cavity Conditioner was applied to dentin and cementum surfaces of the specimens and left undisturbed for 10 seconds; rinsed with water for 10 seconds; gently air dried for 5 seconds, leaving a moist surface. Mix capsules for 10 seconds; then it was applied directly through the plastic tube as with .resin composite; light cure for 20 seconds

\section{Shear bond strength testing}

All the specimens were then transferred to the Instron universal machine individually and subjected to shear bond strength analysis at cross head speed of $1.0 \mathrm{~mm} /$ min. The shear load was applied as close as possible to the adhesive interface utilizing a blunt knife-edged apparatus and the maximum load required for de-bonding. The values obtained were calculated in Mega Pascal (MPa) peak load at failure divided .by the specimen surface area

\section{Statistical analysis}

The data were statistically analyzed using Kolmogorov-Smirnov and Shapiro.Wilk tests and the Student's t-test

\section{RESULTS}

The mean and standard deviation values were calculated for each group in each test. Data were explored for normality using Kolmogorov-Smirnov and Shapiro-Wilk tests, data showed parametric (normal) distribution.

Independent sample t-test was used to compare between two groups in non-related samples. Paired wise sample t-test was used to compare between two groups in related samples.

The significance level was set at $\mathrm{P} \leq 0.05$. Statistical analysis was performed with IBM® SPSS ${ }^{\circledR}$ Statistics Version 20 for Windows.

\section{I) Shear bond strength results}




\section{1) Effect of material}

\section{a) Dentin}

No statistically significant difference was found between (Resin composite) and (Resin modified glass ionomer) where $(p=0.087)$.

The highest mean value was found in (Resin composite), while the lowest mean value was found in (Resin modified glass ionomer).

\section{b) Cementum}

A statistically significant difference was found between (Resin composite) and (Resin modified glass ionomer) where $(p=0.032)$.

The highest mean value was found in (Resin modified glass ionomer), while the lowest mean value was found in (Resin composite).

\section{Effect of tooth structure}

\section{Resin Composite (a}

No statistically significant difference was found between (Dentin) and (Cementum) where ( $\mathrm{p}=0.224)$.

The highest mean value was found in (Dentin),

Table (2): The mean standard deviation (SD) of shear bond strength in different groups

\begin{tabular}{|c|c|c|c|c|c|}
\hline \multirow{3}{*}{ Variables } & \multicolumn{4}{|c|}{ Shear bond strength } & \multirow{3}{*}{$\mathrm{p}$-value } \\
\hline & \multicolumn{2}{|c|}{ Resin composite } & \multicolumn{2}{|c|}{ Resin modified Glass ionomer } & \\
\hline & Mean & $\mathrm{SD}$ & Mean & $\mathrm{SD}$ & \\
\hline Dentin & 17.26 & 5.03 & 13.26 & 1.12 & $0.087 \mathrm{~ns}$ \\
\hline Cementum & 13.61 & 2.07 & 20.31 & 6.24 & $* 0.032$ \\
\hline p-value & \multicolumn{2}{|c|}{$0.224 \mathrm{n} 5$} & \multicolumn{2}{|c|}{$0.050 \mathrm{n} 5$} & \\
\hline
\end{tabular}

*; significant $(p<0.05) n s ;$ non-significant $(p>0.05)$

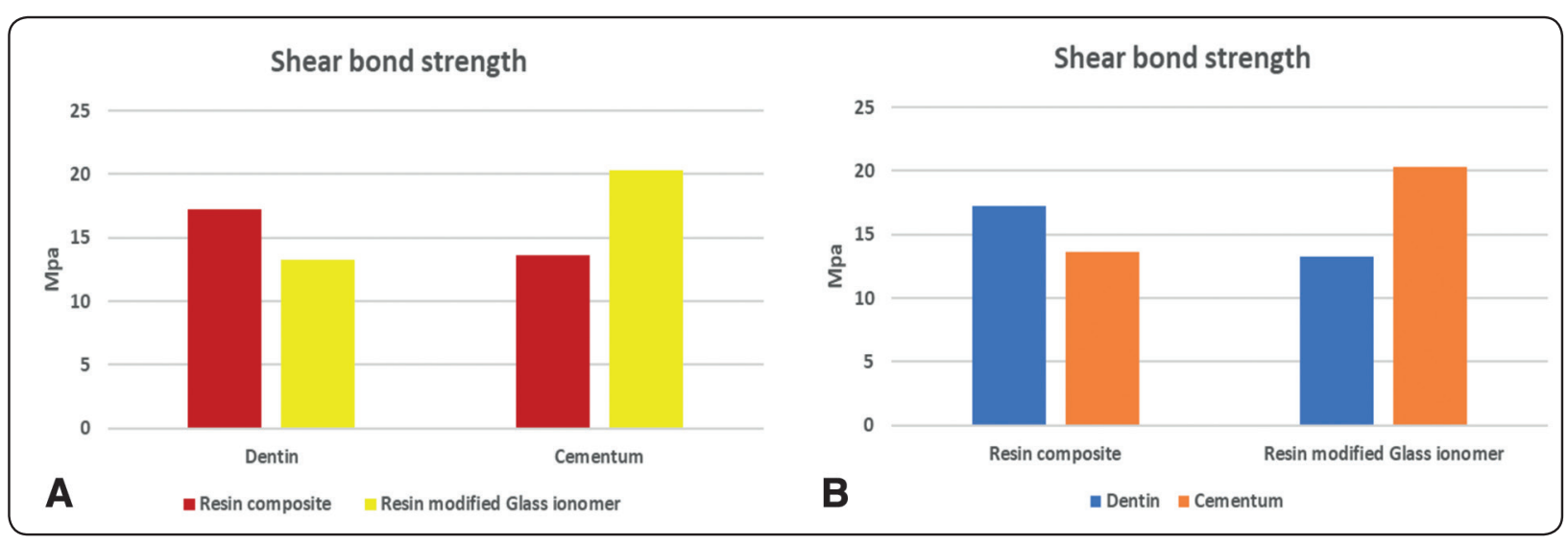

Fig. (1): Bar chart representing shear bond strength for different groups 
while the lowest mean value was found in (Cementum).

\section{Resin modified glass ionomer (b}

No statistically significant difference was found between (Dentin) and (Cementum) where $(p=0.050)$.

The highest mean value was found in (Cementum), while the lowest mean value was found in (Dentin).

\section{DISCUSSION}

The root cementum has high organic content and predominantly consists of cross-linked collagen structure. This type is less hard and more permeable than enamel and dentin ${ }^{(14) .}$ New adhesive systems have been developed in an attempt to obtain reliable bonding to all tooth substrates. Two different approaches are the most frequently used the etch and rinse system and the self-adhesive system and recently the universal adhesive systems. The presence of MDP in some universal adhesive systems allowed ionic bonding with tooth substrates, but still little is known about their ability to interact with dentin and cementum ${ }^{(15)}$.

This study was conducted to evaluate the shear bond strength of resin modified glass ionomer cement (RMGIC) and the resin composite using universal adhesive containing MDP on different tooth substrates cervical dentin and cementum. In this study dentin and cementum specimens were obtained from the same tooth for more standardization of the chemical composition and the degree of mineralization when comparing both substrates with each other. Shear bond strength was used in this study to evaluate the bonding efficacy, as this test is considered relatively simple that permits efficient screening of the adhesive systems. It is a variable test when evaluating brittle materials having low modulus of elasticity as RMGIC as it lowers the probability of having a crack opening relative to load applied.

Results of the present study revealed that there was no statistical difference in the shear bond strength between cervical dentin and cementum using resin composite with universal adhesives and these findings was in contradiction with Hiroshi et $\mathrm{al}^{(18)}$ whom found that the shear bond strength of universal adhesives was low with cementum. Also, Dijken et al ${ }^{(17)}$ found moderate to severe leakage at the area below cemento-enamel junction at the cementum when evaluating the bonding to cementum using resin composite. Also in this study it was found out that the shear bond strength of RMGIC to cementum was higher than that of resin composite using universal adhesive system which may be due the high organic content of cementum which may compromise $33 \%$ by weight, also the conditioning step with polyacrylic acid allows for partial demineralization giving the opportunity for the HEMA component to enhance the wetting of the surface and the production of micro porosity in the different tooth substrates, which may contribute to either increased surface area for chemical bonding with residual hydroxyapatite or micro-mechanical bonding through micro-mechanical interlocking. These results agreed with Daisake Kikushima et $\mathrm{al}^{(19)}$ who found that the cementum showed lower micro shear bond strength than for dentin using two step self-etch adhesive systems and they explained this due to the existence of coarse collagen fibers which may cause less or inhomogeneous penetration of resin monomers.

As general comparison of the results of shear bond strength of resin composite and RMGIC on cervical dentin, it revealed no statistically significant difference and this may be attributed to the chemical bond of RMGIC by ionic exchange between the RMGIC and the dentin substrate, the penetration and further the light curing of RMGIC through the smear layer into the dentinal tubules provide an additional mechanical interlocking of the polymer to 
dentin ${ }^{(15,16)}$. These results were in contradiction with D.A Abo. AL Hana et $\mathrm{al}^{\left({ }^{(8)}\right.}$ whom claimed that resin composite had higher micro shear bond strength than RMGIC, and this may be due to using the micro shear bond strength test rather than shear bond strength test that gave more homogenous and lower dimensions of the specimens and the size of contact surface stress concentration is also decreased.

In the present study it was claimed that there were no statistically significant difference of resin composite using universal adhesive containing MDP on the shear bond strength of dentin and cementum, also no statistically significant difference between the resin composite and RMGIC on the dentin substrate, while there was statistical significant difference when used with cementum showing higher shear bond strength with the RMGIC, furthermore, no statistically significant difference between RMGIC and resin composite on shear bond strength when comparing cervical dentin and cementum.

\section{CONCLUSION}

Under the conditions of the present study, the following conclusions could be derived:

Resin composite using universal adhe$1-$ sive containing MDP showed equal performance to different tooth substrates cervical dentin and cementum

The resin modified glass ionomer ce$2-$ ment showed equal performance on different tooth substrates on cervical dentin and cementum

Resin modified glass ionomer cement 3showed prompt bonding to cementum than that of resin composite

\section{REFRENCES}

1. Beznos C. Microleakage at the cervical margin of composite class II cavities with different restorative techniques. Oper Dent 2001; 26:60-69

2. Ferrari M, Cagidiago MC, Davidson C. Resistance of cementum in class II and V cavities to penetration by an adhesive system. Dent Mater 1997; 13:157-162

3. Demarco FF, Ramos OLV, Mota CS, Formolo E, Justino LM. Influence of different restorative techniques on microleakage in class II cavities with gingival wall in cementum. Oper Dent 2001; 26:253-259

4. Tay FR, Kwong SM, Itthagarun A, King NM, Yip HK, Moulding KM, Pashley DH. Bonding of a self-etching primer to noncarious cervical sclerotic dentin: interfacial ultrastructure and microtensile bond strength evaluation. J Adhesive Dent 2000; 2:9-28

5. Nakajima M, Sano H, Burrow MF, Tagami J, Yoshiyama M, Ebisu S, Ciucchi B, Russell CM, Pashley DH. Tensile bond strength and SEM evaluation of caries affected dentin using dentin adhesives. J Dent Res 1995; 74:1679-1688.

6. Cagitiaco MC, Ferrari M, Vichi, Davidson CL. Mapping of tubule and intertubule surface areas available for bonding in class V and class II preparations. J Dent 1997; 25:379-389.

7. Kolker JL, Vargas M, Armstrong SR, Dawson D. Effect of desensitizing agents on dentin permeability and dentin tubule occlusion. J Adhesive Dent 2002; 4:211-221.

8. D.A. Abo Al Hanan and H.A. Alhadainy.Microshear bond strength of different composites and glass ionomers used to reinforce root dentin. Tanta Dental journal. Vol. 10, Iss. 2, 58-66, August 2013.

9. Tay FR, Gwinnett AJ, Pang KM, Wei SHY. Variability in microleakage observed in a total-etch wet-bonding technique under different handling conditions. J Dent Res 1995; 74:1168-1178.

10. D. Tziafas.Composition and Structure of Cementum: Strategies for Bonding. Dental hard tissue and bonding. pp 177-193.

11. Alex, G. universal adhesives: the next evolution in adhesive dentistry? Compend. Contin. Edu. Dent. 36, 1526: 28, 402015

12. BI, S. principles of adhesive dentistry: A theoretical and clinical guide for dentists. PA Aegis Publ. LLc. 8, 125-130, 2013. 
13. Fukegawa, D. etal. Chemical interaction of phosphoric acid ester with hydroxyapatiteJ. Dent.Res. 85, 941-944, 2006.

14. Kaneshiro A.V, Imazato S., Ebisu S., Tanaka Y, Sano H., Tananka S. Effect of self etching resin coating system to prevent demineralization of root surface. Dent. Mater.; 24, 1420-7. 2008.

15. Daisuke Kikushima, Yasushi Shimada, Richard M. Foxton, JungiTagami. Microshear bond strength of adhesive systems to cementum. Am. Journal of Dent. 18(5): 364-8. 2005.

16. Au. Yap, AC Tan, At. Goh, DC. Goh, KC. Chin. Effect of surface treatment and cement maturation on the bond strength of resin modified glass ionomer to dentinJW.
Nicholson. Chemistry of glass ionomer cement. A review. Biomaterials, 19; 485-494. 1998.

17. van Dijken JW. Clinical evaluation of three adhesive systems in class V non-carious lesions. Dent Mater 2000 Jul; 16(4):285-91

18. Hiroshi Okada, Alirez Sadr, Yasushi Shimada, JunjiTagami. Microshear bond strength of current one step adhesives to cementum and dentin.Am. Journal of Dentistry, 22 (5): 259-63, 2009.

19. Daisuke Kikushima, Yasushi Shimada, Richard M. Foxton, JunjiTagami. Microshear bond strength of adhesive systems to cementum. Am. Journal of Dentistry. 18 (5): 364-8, 2005. 